open in various parts of the operating room and kept open for fifteen minutes and a half hour to see if there was anything in the dust of the room. Cultures were then made from the walls of the operating room by means of swabs on blood agar plates. The same'was done with the skin scrapings from a number of patients after they were prepared as if they were going to be operated upon. Some patients were sterilized by tincture of iodine after their abdomens were eleaned and scrubbed, while another set were sterilized by benzol and iodine. After the cultures were put away in the incubator for 24 hours they were all examined macroscopically and microscopically; they all had one thing or another which was of no importance. There was one set of cultures, however, which proved to be valuable, and that was the set of cultures made from the wall of one of the operating rooms. It contained a beautiful streptococcus hemolyticus. This seemed to throw a light on the investigation and we soon found out that the habit in that hospital was to have a number of adhesive plasters cut and stuck to the wall of the operating room. After the patient was operated on, sterile pads were put on the region where operated and the strips of adhesive plaster from the wall were quickly put on the patient to hold the dressing. This being the case we concluded that the infection was introduced by the adhesive plaster from the wall. The commanding officer of the hospital then ordered all the walls to be washed and repainted, and above all, to stop the habit of sticking the adhesive strips to the walls. In this way, the almost post operative epidemic was stopped.

A SURVEY OF 100 CASES OF DRUG ADDICTION ENTERING CAMP UPTON, N. Y., VIA DRAFT, 1918.

By Ma.jor George E. McPhirson, M.C., (Medfted, MĀ̄s.), Camp Psychiatrist, ÁND

I ieut. Joseph Cohen, Ph.D., (New York City), Examiner, Division of Psychology.

EARLY in June of this year, it became noticeable that a relatively large number of drug addicts were being received at camp. These men passed before selected examining teams, and, as suspected cases, were sent before a spe- cial board for disposition. Statistics prepared at the time of writing this paper show that of all the rejections in five months, under the Neuro-Psychiatric Service at this camp, 17\% were drug addicts, which indicates the importance of this disease. During the five months from May to September, inclusive, 53,000 recruits were examined. In this period of time 178 drug addicts were rejected, approximating $0.35 \%$ of the total number of drafted men.

Previous experience in accepting these recruits for service; attempting to treat them with hope of improvement at the base hospital, had so uniformly and ingloriously failed, that the policy of rejecting all positive cases was instituted in June. Most of such men gave a history of numerous trials at various "cures" whose failure was apparently. complete.

Where the statement of the recruit was substantiated by positive physical symptoms of withdrawal, or in those cases exhibiting recent corroborative marks of hypodermic needles, such men were at once rejected from the draft and returned to civil life as unfit for military service; otherwise suspects were sent to duty or to the base hospital for further observation. It was found to be perfectly practicable to observe these men in their companies and to have distress relieved by the battalion surgeons, until the necessary discharge papers could be procured and these men dismissed from camp.

A considerable number of such addicts begged for a chance to stay in the service, apparently thinking the army life offered a cure where other attempts had failed. Several. were allowed to try it, even against one's better judg. ment, and without other assistance than regular life and reasonable physical exercise. Most of such experiments failed and emphasized the poor material from which such addicts are fashioned. Although not grading low psychologically, these men are below par in moral sense, judgment or perseverance in good habits.

About July 1 it was decided, with the coöperation of the Psychological Division, to attempt the examination of a set number of drug addicts; to grade them psychometrically; to obtain their histories; all with the hope that the resulting information might prove instivetive. Certain it is that.in the large cities the Federal law does not successfully suppress the traffic in narcotics. The majority of thase men who had drugs in their possession exhibited vials 
with drug-store labels and had "permits" from physicians to facilitate the obtaining of drugs.

A large percentage of these men coming into camp had been caught without sufficient supply of drugs, so that they were, in the majority of instances, suffering more or less acutely from their withdrawal. Eighteen men were in good physical condition and showed no mental distress. The remainder $(82 \%)$ exhibited symptoms varying from feelings of weakness and drowsiness on one hand to conditions of exhaustion, and collapse on the other. Marked tremors, especially facial, sweats, abdominal cramps, often severe, and nervousness emphasized the unhappy condition of those who had run short in their supply.

In an attempt graphically to present the histories of these addicts, fifty cases have been charted. This lot of fifty is entirely representative of the entire survey of one hundred or even more, and is evenly divided between whites and negroes. While it is not the purpose of this paper to prove any set of conclusions, the following résumé deserves some attention.

Mental-Age Ratings (Basic Year, Upper Limit). Mental-age ratings secured by the Stanford-Binet, Point-Scale, Performance-Scale and Beta Tests indicate that the intellectual level of drug addicts appearing before the Recruit Medical Examining Board does not vary strikingly from that of normal draftees. The average for the group and the median (ignoring fractional parts of a year) both lie in year 12.

It is estimated by the Division of Psychology that the average soldier rating is year 14 . While at first it might appear that drug addiction sorrelates closely with mental inferiority, a comparative examination of drug-addict scores with ratings of men of their own social and educational group would reveal that there is no striking intellectual inferiority. The occupational and industrial histories of these men show them to be, in the majority of cases, unskilled or poorly-trained workers whose schooling, in more than half the cases, did not extend beyond the fifth grade. The mental ratings of healthy men within this industrial-educational group is probably not much (if at all) higher than that attained by the average drug addict.

The basic year and upper limit as designated in the table seem to indicate that there is no unusual scatter along the scale. The appear- ance of wide scatter, had it occurred, would usually have been taken to be symptomatic of either a psychotic condition, an attempt at malingering, or of a failure on the part of the subject to coöperate in the work of the examination. On the other hand a gradual dropping off on the scale is assumed to be indicative of perfectly normal mental registration. The "Basic Year" and "Upper Limit" columns, if significant at all, show, therefore, that striking mental deterioration has not yet set in in the variety of cases constituting this group. (Note: Where basic year or upper limit are not registered the scale used was either Performance or Beta.)

Years in United States. Ten of the hundred cases here reported are:foreign-born; the remainder are native-borm. The percentage $(90 \%)$ remains about constant when larger numbers of drug addicts (not here reported upon) are considered. The cases here presented were contributed for the most part by two army drafts, one "white" and one "negro," the exact numerical strength of which it would be difficult to register accurately. It is estimated, however, that the drafts were of equal size. Upon examining the original data sheets (after completing the tabulation) we find the distribution of cases according to race to be: White, 50; African, 50. To compare the incidence of drugaddiction in the two racial groups would necessitate as preliminary a line of geographical demarcation, for it has been found that cases come in groups from certain urban localities and to be comparatively rare in other cities. The drug addict from a rural community seems to be the rery rare exception.

Schooling. More than half of the subjects here reported upon advanced no further than the fifth grade in the elementary schools; $26 \%$ are elementary school graduates; $8 \%$ of the total number reached the high schools. Two in one hundred graduated from a secondary or professional school

Drút.

Addicted to use of heroin exclusively .........42 Addicted to use of morphine exclusively $\ldots \ldots \ldots 20$ Addicted to use of opium exclusively ......... 8 Addicted to use of cocaine exclusively $\ldots \ldots \ldots \ldots \ldots$ 2 Addicted to use of heroin and some other drug 28

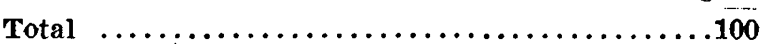

Man ner of Taking Drug.

By hypodermic injection ................64

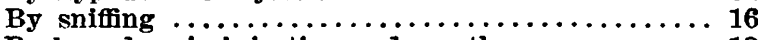
By. hypodermic injection and mouth ........... 12 By smoking .......................... 8

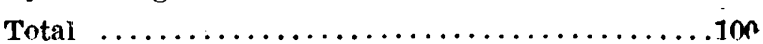


Fufty Drug addict Cases. Comptuation of Mgntal age

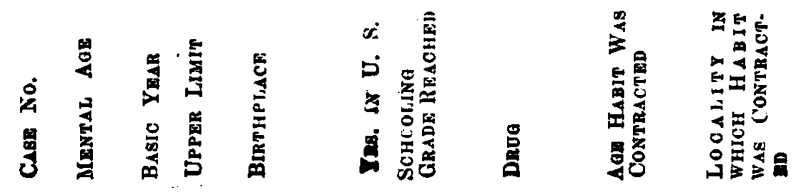

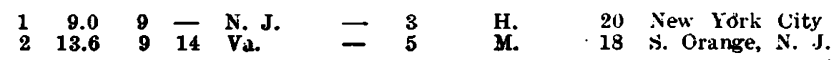

39.09 - N. J. $\quad$ - 4 H., C. \& M. 25 Newark, N. J.

$49.09-$ S. C. $\quad-3 \quad$ H. \& M. 26 Mt. Vernon, N. Y.

$\begin{array}{llllllllll}5 & 11.0 & 9 & 12 & \text { N. C. } & - & 5 & \text { H., } & \text { O. \& M. } 19 \text { New York City }\end{array}$

$\begin{array}{lllllllll}6 & 8.7 & 8 & 9 & \text { Ohio } & - & 8 & \text { H., C. \& M. } 21 & \text { Syracuse, N. Y. }\end{array}$

$\begin{array}{llllllllll}7 & 15.2 & 10 & 18 & \text { N. Y. } & - & 8 & \text { M. } & 19 & \text { Troy, N. Y. }\end{array}$

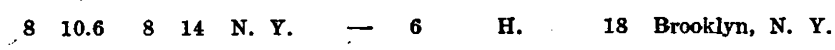

$99.09-$ Va. $\quad-7 \quad$ H. \& C. 16 Newark. N. J .

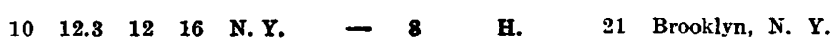

$\begin{array}{llllll}11 & 14.4 & 10 & 16 & \text { N.R. } & -\end{array}$

$\begin{array}{lllllll}12 & 10.8 & 10 & 12 & \text { N. R. } & -\quad 3\end{array}$

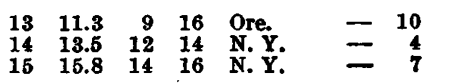

$\begin{array}{lllllll}16 & 9.9 & 8 . & 14 & \text { Ituly } & 20 & 0\end{array}$

$\begin{array}{lllllll}17 & 14.00 & 14 & 14 & \text { N. Y. } & -6\end{array}$

$\begin{array}{lllllll}18 & 14.0 & 14 & 14 & \text { N.Y. } & - & 7\end{array}$

$\begin{array}{llllll}19 & 12,8 & 10 & 16 & \text { N.Y. } & -7\end{array}$

$\begin{array}{lllllll}20 & 13.7 & 10 & 16 & \text { Russ. } & 12 & 5\end{array}$

$\begin{array}{lllllll}21 & 15.8 & 14 & 16 & \text { N. Y. } & - \text { H. S. }\end{array}$

$\begin{array}{llllll}22 & 13.0 & 9 & 14 & \text { N. Y. } \quad-6\end{array}$

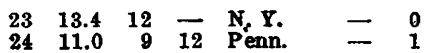

2511.0 - Del. $\rightarrow 0$

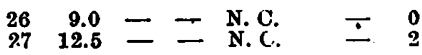

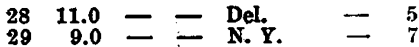

$31 \quad 9.0=$ 二 $\begin{aligned} & \text { Del. } \\ & \text { Del. }\end{aligned}$

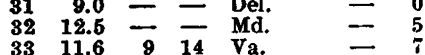

$\begin{array}{lllll}34 & 9.6 & 9 & 10 & \text { Va. } \\ 35 & 11.5 & - & - & \text { Mass. }\end{array}$

$\begin{array}{llllll}36 & 8.7 & 8 & 9 & \text { N. Y. } & -6\end{array}$

$\begin{array}{lrrrll}37 & 12.4 & 9 & 14 & \text { N.Y. } & \\ 38 & 8.5 & 8 & 9 & \text { Rumania } & \\ 3 & 11.1 & 9 & 14 & \end{array}$

\begin{tabular}{lllll}
39 & 11.1 & 9 & 14 & N.Y. \\
\hline
\end{tabular}

$\begin{array}{lllll}40 & 14.8 & 12 & 16 & \text { Denmark }\end{array}$

$\begin{array}{lrrrl}41 & 9.5 & 9 & 10 & \text { Conn. } \\ 42 & 15.8 & 14 & 18 & \text { N.Y. } \\ 13 & 14.0 & 12 & 14 & \text { N.Y. }\end{array}$

$\begin{array}{llllllr}44 & 13.1 & 10 & 14 & \text { Penn } & & 8 \\ 45 & 16.7 & 14 & 18 & \text { Canada } & 10 & 10\end{array}$

$\begin{array}{llllll}46 & 13.3 & 12 & 14 & \text { Masa } & -11\end{array}$

$\begin{array}{lllllll}17 & 11.3 & 9 & 14 & \text { Ala. } & - & 4\end{array}$

$\begin{array}{lllllll}18 & 15.0 & 14 & 16 & \text { N. Y. } & -8\end{array}$

$\begin{array}{llllll}49 & 13.6 & 10 & 16 & \text { N. Y. } & -1\end{array}$

$\begin{array}{lllllll}50 & 8.3 & 6 & 12 & \text { N. Y. } & -.0\end{array}$
H. 16 New York City

II. 22 Brooklyn, N. Y.

o. 18 China

H.
H.

H. 20 New York City

H. \& C. 16 Brooklyn, N. Y.

H. 19 New York City

H. 19 Brooklyn, N. Y.

M. 19 New York City

H. 20 Staten Island, N. Y.

H. 24 Brooklyn, N. Y.

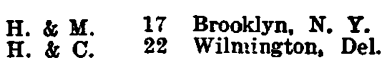

H. \&.f. 19 Wilmington, Del.

$\begin{array}{lll}\text { H. C. } & { }_{22} & \text { Wilmington, Del. } \\ \text { H. Wilmington, Del. }\end{array}$

C. \& H. $\quad 20$ Wilmington, Del.

H. 25 Wilmington, Del.

C. $\quad 19$ Wilmington, Del.

$\begin{array}{llll}\text { H. } & \text { C. } & 22 & \text { Wilmington, } \\ \text { M. \& } & \text { Del. } & \text { Dit } & \text { Brooklyn, i. } \\ \mathbf{Y} .\end{array}$

H. $\quad 20$ New York City

M. 19 Boston, Mass.

H. 17 Brooklyn, N. Y.

M. $\quad 22$ New York City

H. $\quad 24$ New York Gity

M. 24 New York City

H. 18 New Haven, Conn.

o. 20 New York City

M. $\quad 20$ New York City

o. 17 Brooklyn, N. Y.

H.

18 Brooklyn, N. Y.

H.

25 New York City

o. $\begin{array}{lll}\text { H. } & 20 & \text { New York City } \\ \text { H. \& } & 19 \text { New York City }\end{array}$

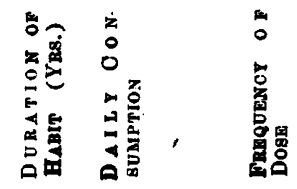

30
$10 \mathrm{gr}$. 6 doses daily Associates

520 ar. 5 doses daily

$920 \mathrm{gr} .4$ " “ Taken by advice of

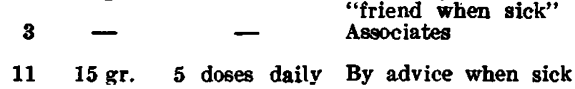

$675 \mathrm{gr} .7$ “ “ A Aseociates

$715 \mathrm{gr}$. 5 “ “

$511 \mathrm{gr} .3$ “ “

1022 or. 4 " “ “ Curiosity

$617 \mathrm{gr} .25$ “ “ A Aseociates

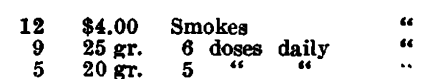

$915 \mathrm{gr}$. 3 . “ “ “ “

7 t12 gr. 4 " " Worry over charge of

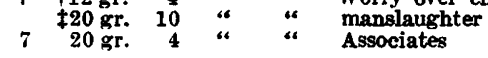

$1040 \mathrm{gr} .10$ " 10 "

; $30 \mathrm{gr} .6$ " 6 "

$410 \mathrm{gr} .4$ “ "

$6 \quad 18 \mathrm{gr} .15$ " 15 "

$350 \mathrm{gr} .8$ “ “ cancer. Medical adv.

$620 \mathrm{kr} .3$ “ 3 a Associates

$950 \mathrm{gr} .8$ “ “ 8

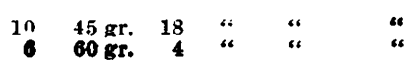

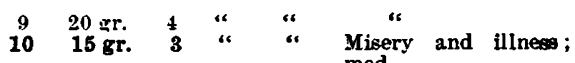

$18 \mathrm{gr}$. 4 “ “ $\begin{aligned} & \text { med. } \\ & \text { Associates }\end{aligned}$

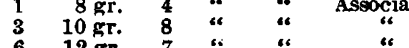

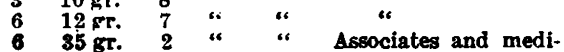

" cation

7 20 gr. 5 “ “ “ “ Associates

$620 \mathrm{gr}$. 20 “ “ “

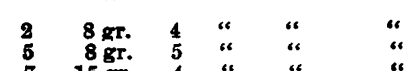

$715 \mathrm{gr} .4$ " “ " 4 "

$520 \mathrm{gr} .4$ “ “ “ $\begin{gathered}\text { Used } \\ \text { vice }\end{gathered}$

18 10 gr. -3 “ “

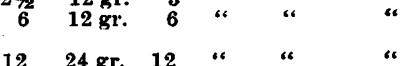

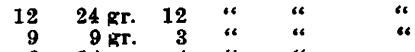

6 14 gr. 4 " . . "

$7 \quad-\quad 2$ smokes d'ly

$412 \mathrm{gr} .4$ doses daily

$31 / 220 \mathrm{gr}$. 5 “ “

12 - Several smokes 
Rating and Pergonal Data. Camp Upton, New York.

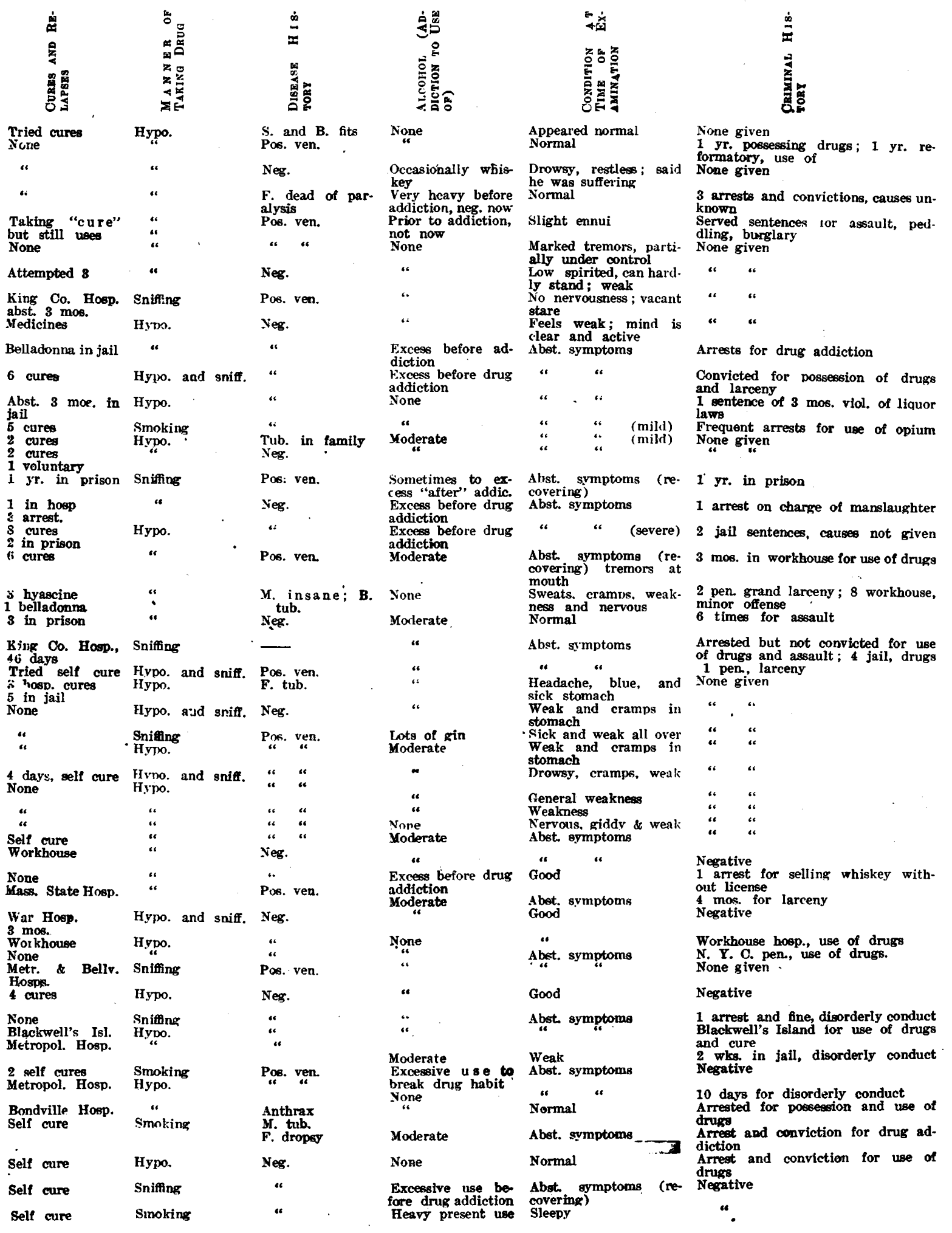


One man smoked $\$ 4.00$ worth of opium per. day. By the hypodermic method one took two, five took three, eleven took four, and four took six doses per day; another took 25 shots in one day. By sniffing, the highest doses per day were three in number. By the combination of sniffing and injection of heroin, respectively, three adults took eight doses of each, and one took twenty doses of each in a day.

Daily Dose. The relationship between age of habit and daily dose immediately suggests itself as a worth-while problem. On the face of the available data, however, no positive conclusion can, be drawn as to the measure of interrelation for the reason that in the vast majority of cases the daily dose is regulated artificially by the limitations of the individual subject's purse. The personal histories of these men reveal the fact that the drug addict usually regulates his budget affairs with a minimum expenditure allowance for the everyday requirements of living, and a correspondingly definite sum for indulgence in his drug. Though the average drug addict would not admit that his habit is an indulgence, the fact remains that the daily dose is usually determined hy the funds available after food and shelter have been secured. The low dose per day was, for morphine, 5 grs.; heroin, 4 grs.; cocaine, 10 grs. The high dose per day was for morphine, 30 grs. ; heroin, 60 grs.; cocaine, 10 grs.

Age at Which Habit was Contracted. Of drug addicts within the old draft age limits (21$31), 72 \%$ contracted the habit before they were 21 years old. The average falls at 19.6 years; many began at 16 , and the oldest in group at 26 .

Manner of Contracting. Ten per cent. of the 100 men examined attributed their contraction to the drug habit to medication by professional advice. Eighty per cent. admitted they were introduced to drugs by their friends, their friends very largely being immoral women. The social stimulus seemed in the large majority of cases to be the active agent in propagating addiction. One such addict told of being kept by a widow for immoral purposes and receiving $\$ 15$ per.week, which he invested largely in drug.

Age of Habit. Of 80 men in this group rejected from the army on account of addiction to drugs,

20 had contracted the habit 6 years prior to this examination.

12 had contracted the habit 7 years prior to this examination.

12 had onntracted the habit 9 years prior to this examination.
10 had contracted the habit 10 years prior to this examination.

20 had contracted the habit 5 years prior to this examination.

6 had contracted the habit 12 years prior to this examination.

The other 20 cases vary widely in this respect (from 1 year to 13 ), although the average $d u-$ ration was 6.76 years.

C'ures Attempted. Of the 100 men examined, 36 attempted to cure themselves at home (usually under guidance of physician); 36 were subjected to hospital cures (usually by involuntary confinement in institutions); 28 addicts declared that they had never tried to break the habit. The 72 who had attempted cures give a total record of 156 unsuccessful attempts. Before drawing conclusions from these data it should be borne in mind that the figures here recorded are based, in many instances, on nothing more authentic than the patient's own statements; the motive for exaggerating and lying about the degree of addiction and dependence upon the drug was, in the case of those eager to evade military service, a strong one; a bona fide cure would from the very nature of the circumstances not be likely to come to the attention of the Neuro-Psychiatric Examining Board.

Use of Alcohol. Teetotalers, 36; moderate users of mild intoxicants, 58 (included in this latter group are 18 who, according to their own accounts, were heavy drinkers prior to their contraction of the drug habit). Six declared that they still drink frequently; a symptom which immediately aroused suspicions about the reliability of their stories. These cases were held over at the base hospital for observation by the medical officer; four were subsequently rejected and two accepted for military service.

Disease Histories. Examination of case histories points to the incidence of venereal disease in at least $38 \%$ of the cases; here, again, the true per cent. may be somewhat higher, for the source of information, in most cases was the patient's own admission or denial. Less than half the total number gave negative histories. There seems to be no distinct connection between the addiction to drugs and hereditary conditions, certainly none that could be obtained from the patients themselves.

Criminal Histories. The total number of "Yes" answers to the question, "Have you ever been arrested?" was 56 . In 18 of these cases the technical charge was that of "Addiction to 
drugs." Excluding arrests and confinements on this charge, there are still 38 who served sentences for criminal offenses varying in seriousness from "disorderly conduct" to "manslanghter." In all there were 54 commitments on charges other than that of addiction to drugs.

Sufficient effort was spent on the drug problem by the Intelligence Department of the camp to bring to light a well established system by which plenty of drugs have been ohtainable, both outside of and within the camp. It is entirely a problem for the eity, not the country district. although the statement has recently been made that the cutting off of alcohol has tended to increase the consumption of drugs in country dis. tricts, and especially in the eities of the South.

As time slipped by evidences arose which bespoke a deliberate attempt to foster and, worse yet, to increase the drug habit for the express purpose of obtaining for the victim a discharge from the Army. So many recently acquiring the habit appeared for examination that suspicions were aroused and enough was found to establish definite propaganda in this edirection. As a solution, a purely local one for the Metriopolitan Distriet of Greater New York, it was suggested by the writer to the City Board of Inebriety, that all drug addicts from New York City be accepted, temporarily at least. for service. By à suitable arrangement such men could be then, by military order, sent to the institution for drug addicts. Here they might well remain as long as necessary for proper observation and classification.

This institution alrealy in existence and with a fairly complete system of records, amplified by possibilities of social service investigations. could readily cull out the old offenders, who might be returned to camp for discharge from the Army. The more recent cases, who might be open to cure under proper treatment, could be returned for duty and sent quickly beyond the likelihood of obtaining the drug. Certainly. if such procedure in such an institution cannot cure such an addict, the Army will prove, by the same token, unable to make him a soldier.

Viewed from any angle at this time, the problem appears to be very largely a civil one, and must take into consideration numerous social factors of extremely baneful influence and which bring their compelling force to bear at a most uufortunate time of a young man's life.

\section{Uliniral Bepartment.}

\author{
REPOR'T OF TWO CASES OF FRACTLRF \\ OF THE CLAVICLE.

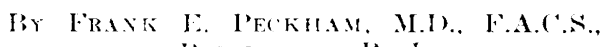 \\ l'rovtheste. Ii. I.
}

In the Boston Medical ini Srraical JourNaI of May 2:3, 1912, I published a method $0^{t}$ treating fractured clavicles.

In the same Journal of April 2:3, 1914, a case of non-union, seven and one-half weeks

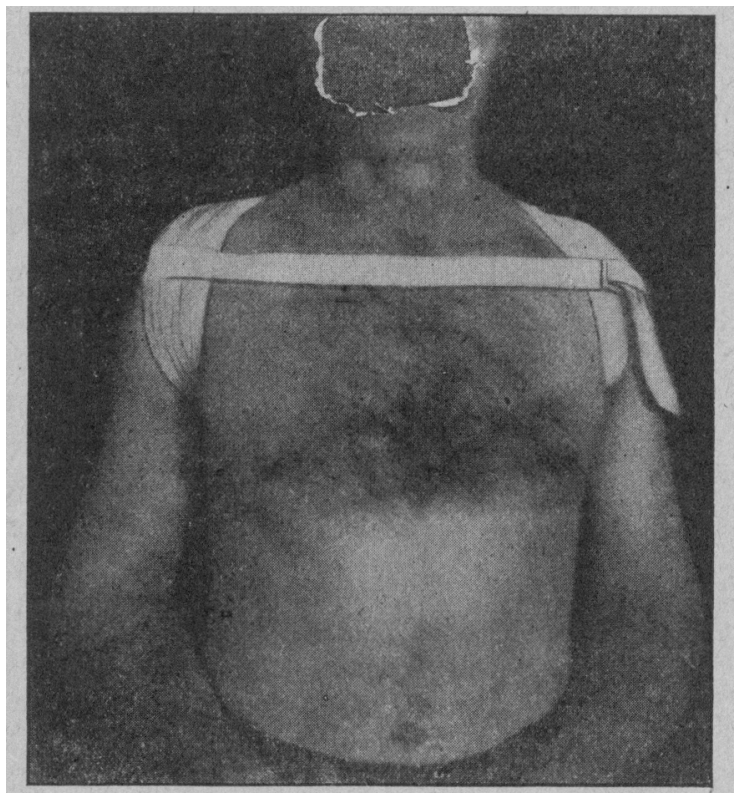

I:AsE I. FIt. 1.-Front view of strap arrangement.

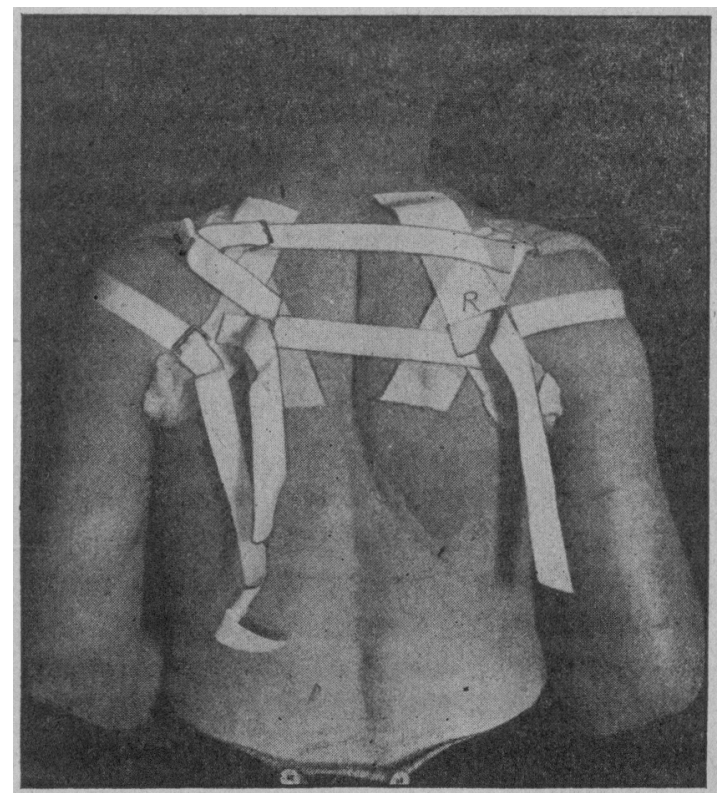

CAsk I. Fia. 2.-Back view of strape. 